(2) Open Access Full Text Article

\title{
Central corneal thickness and intraocular pressure in the Cameroonian nonglaucomatous population
}

This article was published in the following Dove Press journal:

Clinical Ophthalmology

2 July 2010

Number of times this article has been viewed

\author{
André Omgbwa Eballe' \\ Godefroy Koki \\ Augustin Ellong ${ }^{2}$ \\ Didier Owono² \\ Emilienne Epée ${ }^{2}$ \\ Lucienne Assumpta Bella ${ }^{2}$ \\ Côme Ebana Mvogo' \\ Jeanne Mayouego Kouam² \\ 'Faculty of Medicine and \\ Pharmaceuticals Sciences, University \\ of Douala; ${ }^{2}$ Faculty of Medicine and \\ Biomedical Sciences, University of \\ Yaoundé, Cameroon
}

\begin{abstract}
Aim: We performed a prospective, analytical study from 01 January to 31 March 2009 in the Ophthalmology Unit of the Gyneco-Obstetric and Pediatric Hospital of Yaounde, aiming to determine the profile of central corneal thickness (CCT) in the Cameroonian nonglaucomatous black population and its relationship with intraocular pressure (IOP).

Results and discussion: Four hundred and eighty-five patients (970 eyes) meeting our inclusion criteria were selected for this study. The average CCT was $529.29 \pm 35.9 \mu \mathrm{m}$ in the right eye (95\% confidence interval [CI]: 526.09-532.49), 528.19 $\pm 35.9 \mu \mathrm{m}$ in the left eye (95\% CI: $524.99-531.40)$ and $528.74 \pm 35.89 \mu \mathrm{m}$ in both eyes (95\% CI: 526.48-531.00), range 440 to $670 \mu \mathrm{m}$. The average IOP was $13.01 \pm 2.97 \mathrm{mmHg}$ in both eyes (95\% CI: 12.82-13.19). A rise in CCT by $100 \mu \mathrm{m}$ was followed by an increase in IOP of about $2.8 \mathrm{mmHg}$ (95\% CI: $2.3-3.6$ ) for both eyes taken together. Linear regression analysis showed that corneal thickness was negatively correlated with age and IOP was positively related with age.

Conclusion: CCT in the Cameroonian nonglaucomatous black population was found to be lower compared with CCT values in Caucasian and Asian populations. On the basis of reference values ranging between 527 and $560 \mu \mathrm{m}$, an adjustment of IOP values by a correction factor is required for many Cameroonian patients. This will improve the diagnosis and follow-up of glaucoma by helping to detect true ocular hypertension.
\end{abstract}

Keywords: central corneal thickness, intraocular pressure, Cameroon

\section{Introduction}

The accuracy of intraocular pressure (IOP) measurement is considered by some authors to be a "myth" of modern ophthalmology. ${ }^{1}$ During the 1970s, Ehlers and Hansen found a close relationship between IOP values and corneal thickness. ${ }^{2-6}$ Later on, significant changes in IOP values observed by refractive surgeons after EXCIMER laser and, more recently, findings of the multicenter, randomized American Ocular Hypertension Treatment Study (OHTS) in ocular hypertension confirmed that corneal thickness appears to be important when interpreting IOP estimates. ${ }^{7,8}$

In the Cameroonian medical literature, no study has yet been conducted on central corneal thickness (CCT). However, many European and US studies show that Africans and African-Americans have thin corneas. ${ }^{9-11}$ What is the real situation in the Cameroonian nonglaucomatous population? What is the relationship between CCT and age, gender, and IOP? These are the questions that prompted us to carry out a clinic-based study in a sample of normal black Cameroonians with the aim of providing the answers.
Correspondence:André Omgbwa Eballe Department of Ophthalmology, Gyneco-Obstetric and Pediatric Hospital of Yaounde, PO Box 4362, Yaounde, Cameroon

Tel + I I 23799654468

Fax + II 237222 I 2430

Email andyeballe@gmail.com 


\section{Methods}

This was a prospective, analytical study conducted from January 1 to March 31, 2009 in the Ophthalmology Unit of the Gyneco-Obstetrics and Pediatric Hospital of Yaounde, aiming to determine the CTT profile in the Cameroonian nonglaucomatous black population and its relationship with IOP. Subjects included in this study were aged five years or older. Ametropia aside, they were not presenting with any eye disease and had never undergone eye surgery. Patients with diabetes, high IOP, infectious or inflammatory conjunctival or uveal diseases, corneal dystrophy, or need for contact lenses, were excluded, along with known glaucomatous subjects.

Participants underwent a complete bilateral ophthalmologic examination, including assessment of visual acuity with a Snellen chart, slit lamp examination of the anterior and posterior segments of the eye, fundoscopy, air-puff tonometry and objective refraction. CCT was measured using a hand-held ultrasonic pachymeter (Quantel Medical). This instrument has high reliability, with an ultrasound transmission speed of $1640 \mathrm{~m} / \mathrm{sec}$. Pachymetry was performed during the daytime between 8:00 am and 1:00 pm by the same examiner, one eye after the other. After corneal anesthesia with Cebesine ${ }^{\circledR}$, the probe was placed in the center of the cornea perpendicular to the pupil axis. Three measurements were taken, and the smallest was considered as that corresponding to the real center of the cornea. Three measurements of IOP were also made using a noncontact tonometer (TOPCON) and the average value displayed by the tonometer was the one considered for each eye. We considered IOP values $\leq 21 \mathrm{mmHg}$ and CCT values ranging from 527 to $560 \mu \mathrm{m}$ as normal. Corneas with a central thickness value below $527 \mu \mathrm{m}$ were considered as thin and those with a central thickness value above $560 \mu \mathrm{m}$ were considered as thick corneas. ${ }^{12}$

Variables analyzed were gender, age, IOP, and CCT. Data analysis was performed using SPSS software (SPSS Inc., Chicago, IL). A descriptive analysis was first done in order to bring out the main trends from the data. This analysis was based on statistical tests with a significant threshold of $5 \%$ $(P<0.05)$. Several variants of the Student $t$-test were used. These included notably the Student $t$-test for comparing an average value with a reference one (one-sample $t$-test), which made possible the comparison of the average CCT in the Cameroonian population with that obtained previously for other countries. The comparison of CCT between the right and left eyes was done using the Student $t$-test related to paired samples. The test for analysis of variance (ANOVA) was used to highlight a possible change in corneal thickness with age. Comparison of CCT and IOP between men and women was done using the independentsamples $t$-test. Analysis of the relationship between CCT and IOP was done using several tests, including the ANOVA test, chi-square test for independence, and Pearson linear correlation test. All these methods led to convergent and consistent results, demonstrating the existence of a relationship between CCT and IOP. A confirmation was established with models of multivariate linear regression involving not only these two variables, but also age and gender. The significance threshold used in this part of the study was also equal to $5 \%(P<0.05)$. We then calculated the pressure-to-cornea index (PCI) using the formula IOP/ CCT3 for each eye and both combined. A PCI range of 120-140 was proposed as the upper limit of "normality", with 120 being the cutoff value for eyes with untreated pressures $\leq 21 \mathrm{mmHg} .{ }^{13}$

\section{Results}

Four hundred and eighty-five patients (970 eyes) meeting our inclusion criteria were selected for this study. Our sample comprised 163 men (33.6\%) and 322 women (66.4\%) whose ages ranged from five to 75 years with an average of $31.4 \pm 15.5$ years; the average age was $32.8 \pm 16.1$ in men and $30.6 \pm 15.1$ years in women. The most representative age group was 20-39 years which accounted for $44.1 \%(n=214)$ of patients. The average IOP was $12.95 \pm 2.95 \mathrm{mmHg}$ in the right eye (95\% confidence interval [CI]: 12.69-13.21), $13.06 \pm 2.98 \mathrm{mmHg}$ in the left eye (95\% CI: $12.80-13.33$ ) and $13.01 \pm 2.97 \mathrm{mmHg}$ in both eyes (95\% CI: 12.82-13.19). The average IOP in men was $12.98 \pm 2.91 \mathrm{mmHg}$ and the average IOP in women was $13.02 \pm 2.99 \mathrm{mmHg}$ without any statistically significant difference $(P=0.83$, independent samples $t$-test). IOP was positively correlated with age (Figure 1). The average CCT was $529.29 \pm 35.9 \mu \mathrm{m}(95 \%$ CI: 526.09-532.49) in the right eye, $528.19 \pm 35.9 \mu \mathrm{m}$ in the left eye (95\% CI: 524.99-531.40) and 528.74 $\pm 35.89 \mu \mathrm{m}$ in both eyes (95\% CI: 526.48-531.00), range 440-670 $\mu \mathrm{m}$ (Table 1).

\section{Central corneal thickness and gender}

The average CCT in both eyes was $530.27 \pm 34.83 \mu \mathrm{m}$ among men (95\% CI: 526.47-534.06) and $527.97 \pm 36.41 \mu \mathrm{m}$ among women (95\% CI: 525.15-530.79) with no significant difference $(P=0.35$, independent-samples $t$-test, Table 1). 


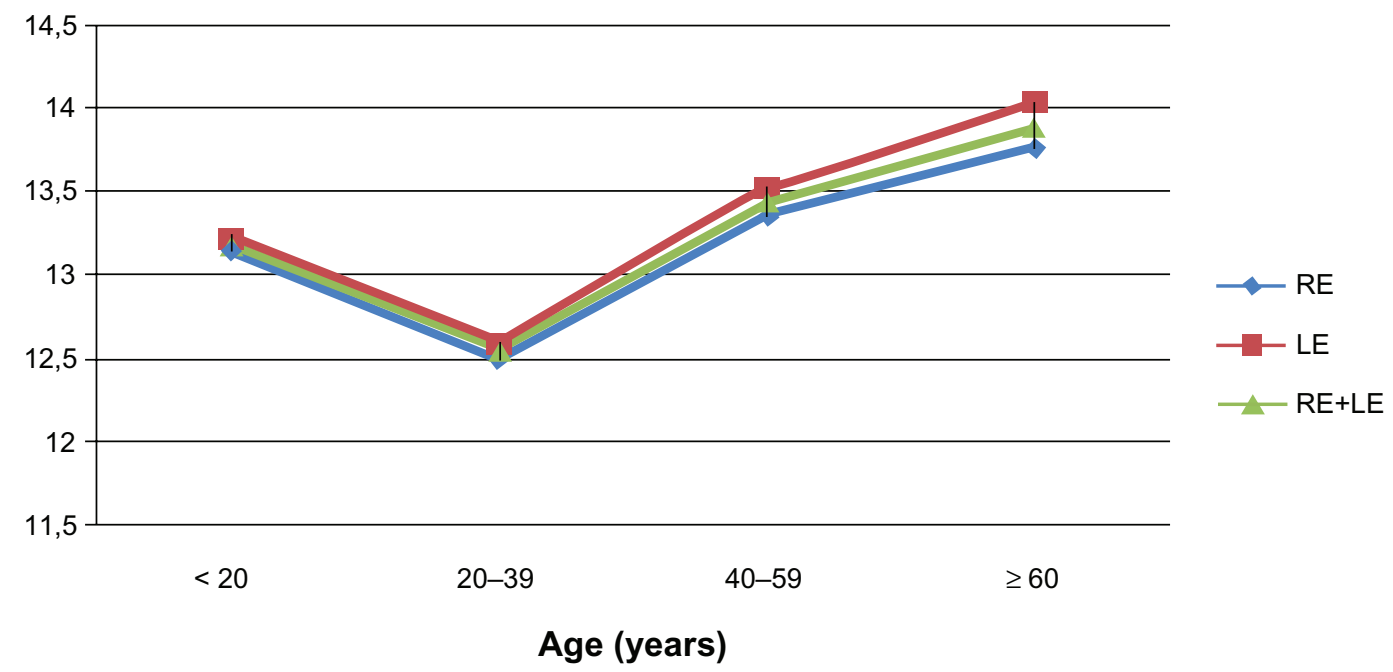

Figure I Intraocular pressure according to age ( $n=970$ eyes).

Abbreviations: LE, left eye; RE, right eye.

\section{Central corneal thickness and age}

Figures 2 and 3 show that CCT decreases with age, irrespective of gender. The cornea was thicker in the group of patients aged younger than 20 years, with an average of $537.63 \pm 37.27 \mu \mathrm{m}$ in the right eye, $536.74 \pm 37.87 \mu \mathrm{m}$ in the left eye, and $537.19 \pm 37.50 \mu \mathrm{m}$ in both eyes. CCT was thinner among the group of patients aged more than 60 years $(P<0.05$, one-way ANOVA). However, Table 2 shows with more detail that whichever the eye, CCT significantly decreased with age among women ( $P=0.005$, one-way ANOVA). In the men this decrease was not statistically significant $(P>0.05$, one-way ANOVA). In general, the linear regression analysis shows that corneal thickness is negatively related to age. Indeed, CCT decreases by $4.2 \mu \mathrm{m}$ per 10 years. This decrease is about $4.0 \mu \mathrm{m}$ in the right eye and $4.3 \mu \mathrm{m}$ in the left eye per 10 years (Table 3 ).

\section{Central corneal thickness and standard values}

Two hundred thirty-four subjects (48.24\%) had thin corneas $(\mathrm{CCT}<527 \mu \mathrm{m})$ in the right eye with an average of $500.48 \pm 20.93 \mu \mathrm{m}$ (95\% CI: 497.80-503.16). In the left eye, there were 240 patients presenting with thin corneas (49.48\%) with an average of $500.03 \pm 20.66 \mu \mathrm{m}$ (95\% CI: 497.41-502.64). Eighty-seven right corneas $(17.93 \%)$ and 82 left corneas $(16.9 \%)$ were found to be thick $(\mathrm{CCT}>560 \mu \mathrm{m})$ with a respective average of $582.44 \pm 21.33 \mu \mathrm{m}$ and $583.55 \pm 20.44 \mu \mathrm{m}(95 \%$ CI: 577.95-586.12 and 579.12-587.97, respectively). Thirty corneas $(3.09 \%)$ had a CCT above $600 \mu \mathrm{m}$. There were 164 corneas (33.81\%) with normal CCT (range 527-560) in the right eye with an average of $542.20 \pm 9.65 \mu \mathrm{m}$, and 163 in the left eye (33.60\%) with an average of $542.01 \pm 9.80 \mu \mathrm{m}(95 \% \mathrm{CI}$ : $540.72-543.68$ and $540.29-543.35$, respectively).

\section{Central corneal thickness and intraocular pressure}

The more the CCT rose, the greater was the IOP (Figure 4). Thus, among the thin cornea group, the average IOP in both eyes was $12.32 \pm 2.94 \mathrm{mmHg}$. This was $13.06 \pm 2.76 \mathrm{mmHg}$ in the group with normal CCT and $14.82 \pm 2.64 \mathrm{mmHg}$ among the thick cornea group. This difference was

Table I Central corneal thickness according to gender

\begin{tabular}{|c|c|c|c|c|c|c|}
\hline \multirow[t]{2}{*}{ Gender } & \multicolumn{2}{|l|}{ RE CCT } & \multicolumn{2}{|l|}{ LE CCT } & \multicolumn{2}{|l|}{ RE + LE CCT } \\
\hline & Average & $\mathbf{n}$ & Average & $\mathbf{n}$ & Average & $\mathbf{n}$ \\
\hline Male & $530.52 \pm 34.97$ & 163 & $530.02 \pm 34.80$ & 163 & $530.27 \pm 34.83$ & 326 \\
\hline Female & $528.67 \pm 36.40$ & 322 & $527.27 \pm 36.47$ & 322 & $527.97 \pm 36.41$ & 644 \\
\hline Total & $529.29 \pm 35.90$ & 485 & $528.19 \pm 35.90$ & 485 & $528.74 \pm 35.89$ & 970 \\
\hline$P * *$ & 0.593 & & 0.426 & & 0.347 & \\
\hline
\end{tabular}

Abbreviations: CCT, central corneal thickness; LE, left eye; RE, right eye.

Notes: ${ }^{* *}$ Independent-samples $t$-test. 


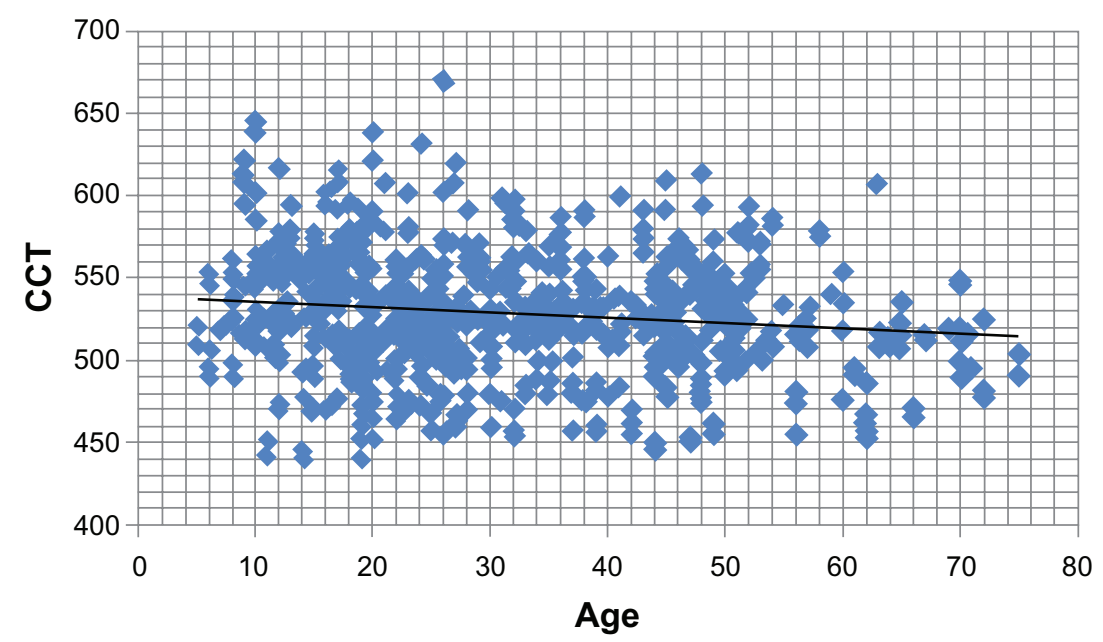

Figure 2 Scattergram of central corneal thickness (CCT) versus age $(n=970$ eyes).

statistically significant $(P<0.05$, one-way ANOVA, Figure 5). Pressure-to-cornea index (PCI) in the right eye was $88.50 \pm 23.06$ and $89.78 \pm 23.31$ in the left eye $(P>0.05)$; in both eyes (right and left combined) PCI was $89.14 \pm 23.19$.

\section{Discussion}

The CCT of nonglaucomatous black Cameroonian subjects is comparable with that found in other African and African-American populations ${ }^{9-11}$ in which people have thin corneas. Moreover, this may explain the relatively low values of IOP found in Africans and African-Americans. ${ }^{14-17}$ On ultrasound pachymetry, the average CCT in Caucasians is $544 \pm 34 \mu \mathrm{m} .{ }^{14,15,18}$ This is significantly higher than the average $\mathrm{CCT}$ found in the Cameroonian population, ie, $528.74 \pm 35.89 \mu \mathrm{m}(P<0.05$, one-sample $t$-test $)$ for right and left eyes combined. Therefore, it would be prudent to integrate this data as a working basis during glaucoma consultations or in the future when practising refractive surgery in Cameroon. A CCT above $600 \mu \mathrm{m}$ is found in less than $5 \%$ of normal subjects. ${ }^{14,15}$ In our study, we found a frequency of $3.09 \%$ which is consistent with the reports in the literature.

Several studies have revealed a significant correlation between CCT and gender, reporting that CCT is slightly higher in men compared with women, ${ }^{11,19-21}$ whereas other investigators did not notice a difference between men and women. ${ }^{22-24}$ In our study, we noticed no statistically significant difference between men and women according to average CCT.

Many studies carried out in Asian populations ${ }^{9,19-21}$ as well as the Barbados Eye Studies ${ }^{17}$ reported a decrease of CCT with age, as was the case in our study, where the

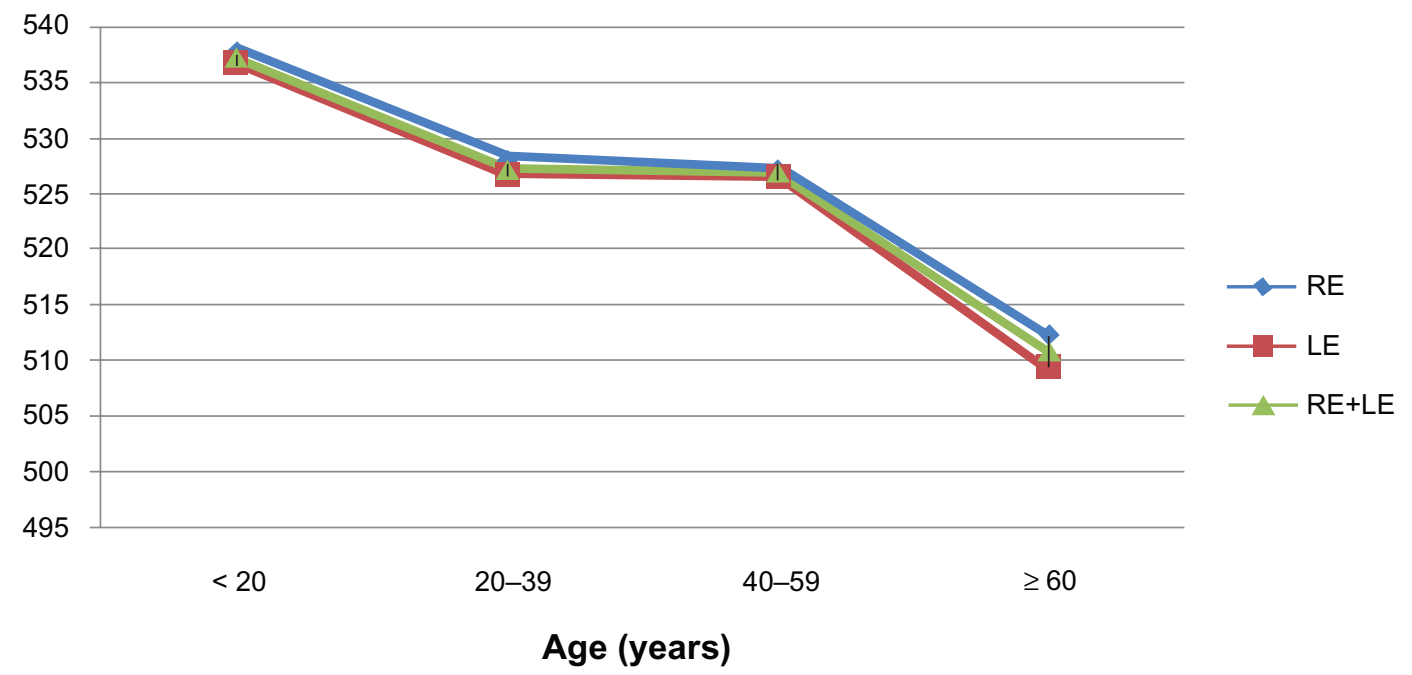

Figure 3 Central corneal thickness according to age ( $n=970$ eyes).

Abbreviations: LE, left eye; RE, right eye. 
Table 2 Central corneal thickness according to age and gender

\begin{tabular}{llllll}
\hline Age (years) & Male & & & Female \\
\cline { 2 - 3 } \cline { 5 - 6 } & RE CCT & LE CCT & & RE CCT & LE CCT \\
\hline$<20$ & $539.85 \pm 38.37(39)$ & $539.90 \pm 37.50(39)$ & & $536.66 \pm 36.95(89)$ & $535.36 \pm 38.16(89)$ \\
$20-39$ & $527.37 \pm 32.44(66)$ & $526.26 \pm 31.38(66)$ & & $528.02 \pm 38.35(148)$ & $526.66 \pm 37.47(148)$ \\
$40-59$ & $528.66 \pm 35.63(47)$ & $529.40 \pm 36.02(47)$ & & $525.90 \pm 30.08(67)$ & $524.10 \pm 30.71(67)$ \\
$\geq 60$ & $524.18 \pm 32.71(11)$ & $520.18 \pm 36.32(11)$ & & $504.83 \pm 27.23(18)$ & $503.00 \pm 27.69(18)$ \\
$P^{*}$ & 0.285 & 0.187 & & 0.006 & 0.005 \\
\hline
\end{tabular}

Abbreviations: CCT, central corneal thickness; LE, left eye; RE, right eye. Note: *One-way ANOVA.

cornea were thinner in patients aged 60 years or older. There is no clear explanation for this finding, although heredity, outdoor lifestyle, and socioeconomic status have been cited as possible influencing factors. ${ }^{25}$ The latter two factors are applicable to the majority of the Cameroonian population, but it was not possible in our study to determine whether the reduction in average CCT related to age represents an acquired phenomenon. Nevertheless, considering gender, the regression of CCT was statistically significant among women, but not among men (Table 2). We may then ask ourselves whether a hormonal factor could be responsible for this observation. This would need to be confirmed by investigations in the future.

Most of the studies carried out on CCT and IOP used the Goldmann applanation tonometer which is indeed the gold standard to measure IOP. In this study, we used an air-puff (noncontact) tonometer. This tonometer is based on the same physical principle, ie, the Imber-Fick principle, which states that the force required to flatten or level a spherical container (W) equals the product of the internal pressure $(\mathrm{P})$ by the area of flattening $(\mathrm{A})$; thus $\mathrm{W}=\mathrm{P} \times \mathrm{A}$. This leveling force depends on several factors, such as the nature of the tear film, corneal curvature, corneal thickness, and corneal rigidity, and is also subject to the influence of CCT because the Goldmann applanation tonometer was calibrated for corneas with a CCT value of $520 \mu \mathrm{m} .{ }^{26}$ A recent comparison by Shepens et $\mathrm{al}^{26}$ of the two types of tonometers demonstrated that there was no statistically significant difference between values given by each tonometer for the same patient.

Numerous studies have reported a positive correlation between IOP measured by Goldmann applanation tonometer and CCT. ${ }^{10,15,16,19-23,27-29}$ Our study shows that there was a positive correlation between CCT and IOP; the more the CCT increased, the higher the IOP became. For both eyes taken together, a rise of CCT by $100 \mu \mathrm{m}$ is followed by an increase in IOP of about $2.8 \mathrm{mmHg}$ (95\% CI: 2.3-3.3). Notably, according to corneal thickness, the IOP rises in the left eye by $2.9 \mathrm{mmHg}$ (95\% CI: $2.2-3.3$ ), and in the right eye IOP increases by $2.7 \mathrm{mmHg}$ (95\% CI: 2.0-3.4). Similarly, other researchers have demonstrated that an increase of the CCT by $100 \mu \mathrm{m}$ induces a rise of IOP in the range of $1.1-3.2 \mathrm{mmHg} .{ }^{18,29-31}$ On the contrary, Foster et al ${ }^{32}$ did not find any relationship between corneal thickness and IOP.

Table 4 shows that IOP rises with age by about $0.29 \mathrm{mmHg}$ every 10 years; the variation in the left eye is about $0.32 \mathrm{mmHg}$ (95\% CI: $0.16-0.48)$ and $0.26 \mathrm{mmHg}$ (95\% CI: $0.10-0.42$ ) in the right eye. The IOP/CCT3 index came close to that worked out by Iliev et al, ${ }^{13}$ which was $92.0 \pm 24.8$ for nonglaucomatous subjects. At the end of their work, they fixed the norm of this index between 120 and 140; the cutoff point for the normal subject being 120, which is similar to our results.

Table 3 Multiple linear regression of central corneal thickness

\begin{tabular}{|c|c|c|c|c|c|c|c|c|c|}
\hline \multirow[t]{2}{*}{ Variables } & \multicolumn{3}{|l|}{ RE } & \multicolumn{3}{|l|}{ LE } & \multicolumn{3}{|c|}{ Combined RE and LE } \\
\hline & Coefficient & $\mathbf{C l}$ & $P$ value* & Coefficient & $\mathrm{Cl}$ & $P$ value* & Coefficient & $\mathrm{Cl}$ & $P$ value* \\
\hline Age & 0.40 & $0.60-0.21$ & 0.000 & 0.43 & $0.62-0.23$ & 0.000 & -0.42 & $0.55-0.28$ & 0.000 \\
\hline IOP & 3.88 & $2.86-4.91$ & 0.000 & 4.12 & $3.11-5.13$ & 0.000 & 4.00 & $3.30-4.71$ & 0.000 \\
\hline \multicolumn{10}{|l|}{ Sex } \\
\hline Male & 3.26 & $3.13-9.64$ & 0.317 & 3.45 & $2.88-9.78$ & 0.285 & 3.37 & I.12-7.85 & 0.141 \\
\hline Female & $\operatorname{Ref}^{\prime}$ & Ref & & Ref & Ref & & Ref & Ref & \\
\hline R-square & & 0.123 & & & 0.138 & & & 0.130 & \\
\hline
\end{tabular}

Abbreviations: CCT, central corneal thickness; $\mathrm{Cl}$, confidence interval; IOP, intraocular pressure; LE, left eye; RE, right eye. Notes: *Student's $t$ - test; 'The modality « Female » is taken here like reference. 


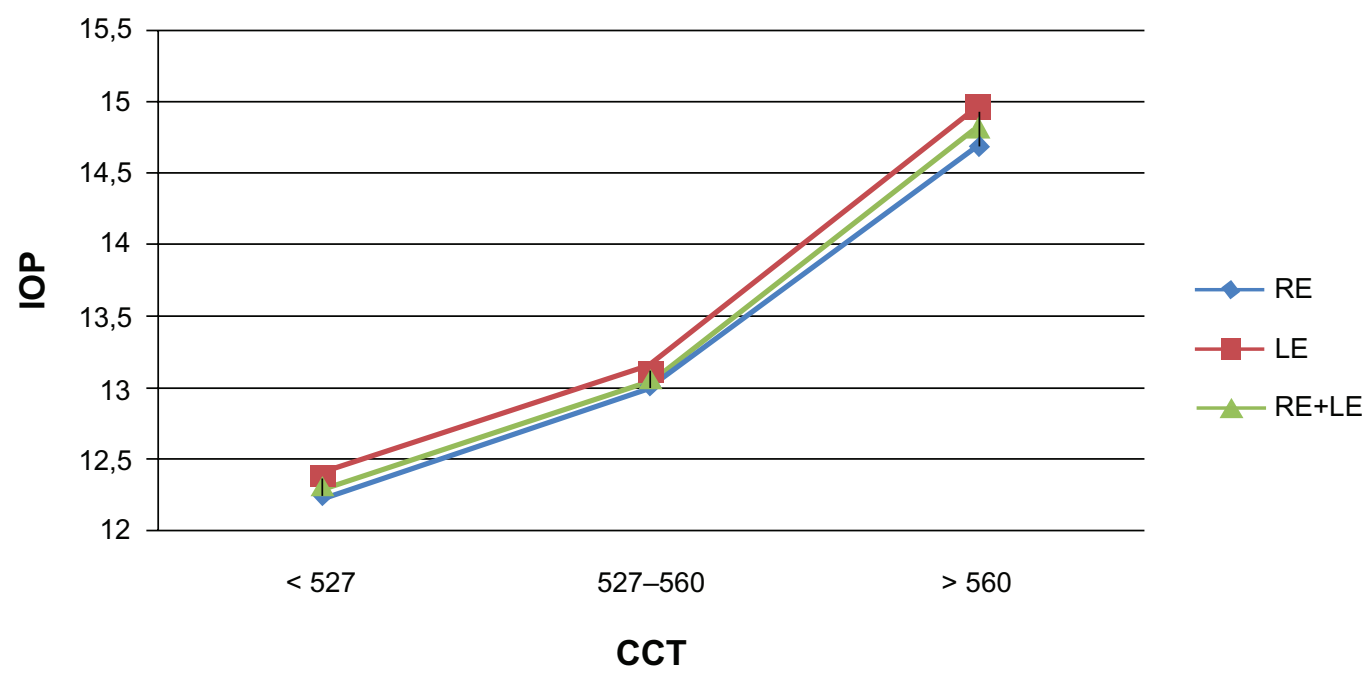

Figure 4 Intraocular pressure (IOP) according to central corneal thickness (CCT) in norm standards $(n=970$ eyes).

Abbreviations: LE, left eye; RE, right eye.

On the basis of reference values ranging between 527 and $560 \mu \mathrm{m},{ }^{12}$ an adjustment of IOP values is required for many Cameroonian patients, namely $48 \%$ of the subjects with thin corneas and $17 \%$ of those with thick corneas, because they represent a considerable proportion of patients subject to IOP measurement errors. Many formulas used to adjust the IOP according to the CCT have been published. However, they have not been unanimously agreed upon. Nonetheless, the unpublished formula suggested by Collignon, taken up again by Detry-Morel, ${ }^{12}$ has the advantage of relying on a linear relationship. Indeed, it advises to add $0.50 \mathrm{mmHg}$ for every $10 \mu \mathrm{m}$ for thin corneas with an average thickness lower than $527 \mu \mathrm{m}$ and to subtract $0.70 \mathrm{mmHg}$ for every $10 \mu \mathrm{m}$ in thick corneas with an average thickness higher than $560 \mu \mathrm{m}$. On the other hand, Doughty and Zaman suggested that the correction for eyes with chronic disease should be 2 or $3 \mathrm{mmHg}$ for each $0.05 \mathrm{~mm}$ difference in CCT from $0.535 \mathrm{~mm} .{ }^{15}$ As long as misunderstandings exist about one and another formula, each ophthalmologist or ophthalmology unit will have to choose an adjustment formula following a reference study.

\section{Conclusion}

CCT values in the Cameroonian nonglaucomatous black population were found to be lower compared with CCT values in Caucasian and Asian populations, but were comparable with those reported in Africans and AfricanAmericans. The average IOP was also lower compared with that found in Caucasians and Asians. CCT is a determining factor in interpreting IOP values. However, very few

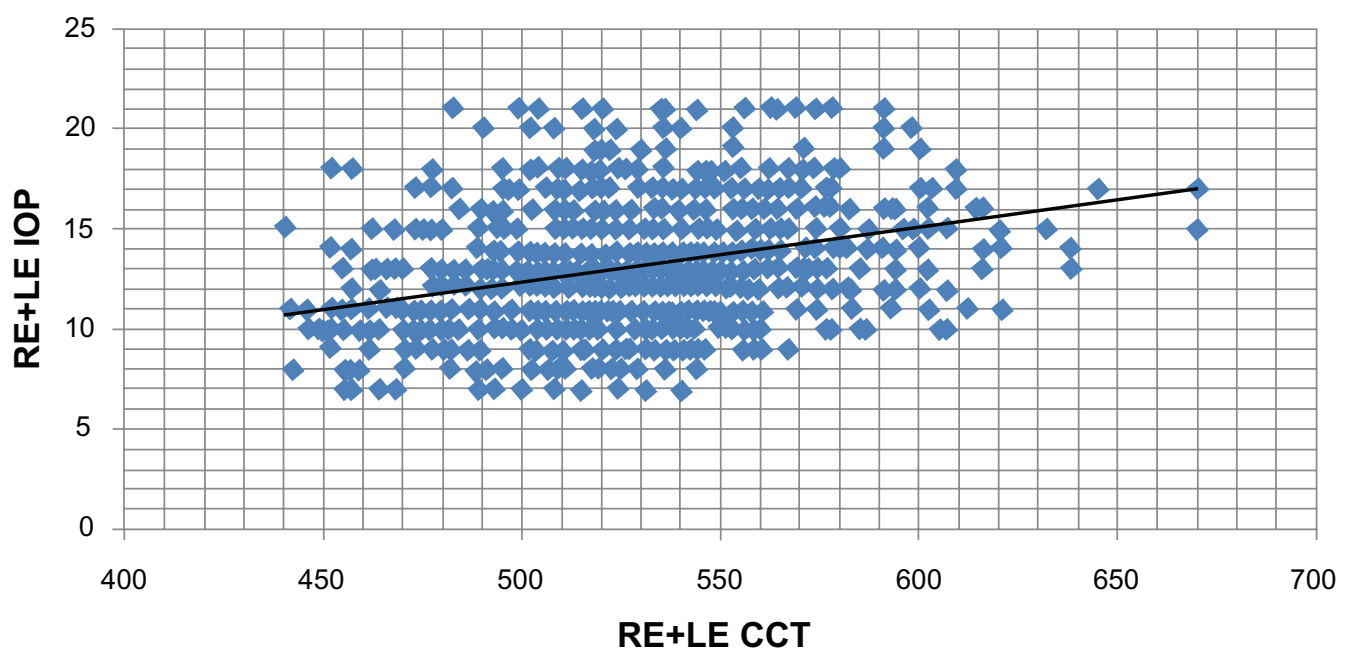

Figure 5 Scattergram between central corneal thickness (CCT) and intraocular pressure (IOP) $(n=970$ eyes). Abbreviations: LE, left eye; RE, right eye. 
Table 4 Multiple linear regression of intraocular pressure

\begin{tabular}{|c|c|c|c|c|c|c|c|c|c|}
\hline \multirow[t]{2}{*}{ Variables } & \multicolumn{3}{|l|}{ RE } & \multicolumn{3}{|l|}{ LE } & \multicolumn{3}{|c|}{ Combined RE and LE } \\
\hline & Coefficient & $\mathrm{Cl}$ & $P$ value* & Coefficient & $\mathbf{C l}$ & $P$ value* & Coefficient & $\mathbf{C l}$ & $P$ value* \\
\hline Age & 0.026 & $0.010-0.042$ & 0.002 & 0.032 & $0.016-0.048$ & 0.000 & 0.029 & $0.017-0.040$ & 0.000 \\
\hline СCT & 0.027 & $0.020-0.034$ & 0.000 & 0.029 & $0.022-0.036$ & 0.000 & 0.028 & $0.023-0.033$ & 0.000 \\
\hline \multicolumn{10}{|l|}{ Sex } \\
\hline Male & -0.243 & $-0.77-0.29$ & 0.367 & -0.093 & $-0.62-0.44$ & 0.729 & -0.168 & $-0.54-0.21$ & 0.378 \\
\hline Female & $\operatorname{Ref}^{\prime}$ & Ref & & Ref & Ref & & Ref & Ref & \\
\hline R square & & 0.111 & & & 0.130 & & & 0.120 & \\
\hline
\end{tabular}

Abbreviations: CCT, central corneal thickness; $\mathrm{Cl}$, confidence interval; LE, left eye; $\mathrm{RE}$, right eye.

Notes: *Student's t-test. 'The modality « Female » is taken here like reference.

ophthalmology departments in Cameroon are equipped with pachymeters. The question arises now about the extent to which ophthalmologists practising in Cameroon should introduce corneal pachymetry in their routine clinical practice. Each Cameroonian with a thin or a thick cornea needs an adjustment of IOP estimates by a correction factor. This will improve both the diagnosis and follow-up of glaucoma, because it will help in detecting true ocular hypertension. Similarly, many cases of normal tension glaucoma or patients falling into the suspected glaucoma category may be found to be genuine glaucomatous patients. Therefore, we recommend a systematic measurement of CCT in routine clinical practice. Furthermore, every ophthalmology unit should be equipped with a pachymeter.

\section{Disclosure}

The authors report no conflict of interest in this work.

\section{References}

1. Shah S. Accurate intraocular pressure measurement. The myth of modern ophthalmology. Ophthalmology. 2000;107:1805-1806.

2. Ehlers N. On corneal thickness and intraocular pressure. II. A clinical study on the thickness of the corneal stroma in glaucomatous eyes. Acta Ophthalmol (Copenh). 1970;48:1107-1112.

3. Ehlers N, Hansen FK. Central corneal thickness in low-tension glaucoma. Acta Ophthalmol (Copenh). 1974;52:740-746.

4. Ehlers N, Hansen FK, Aasved H. Biometric correlations of corneal thickness. Acta Ophthalmol (Copenh). 1975;53:6552-6559.

5. Ehlers N, Bramsen T, Sperling S. Applanation tonometry and central corneal thickness. Acta Ophthalmol (Copenh). 1975;53:34-43.

6. Hansen FK, Ehlers N. Elevated tonometer readings caused by a thick cornea. Acta Ophthalmol. 1971;49:775-778.

7. Mardelli PG, Piebenga LW, Whitacre, MM, Siegmund KD. The effect of Excimer laser photorefractive keratectomy on intraocular pressure measurements using the Goldmann applanation tonometer. Ophthalmology. 1997;104:945-949.

8. Chatterjee A, Shah S, Bessant DA, Naroo SA, Doyle SJ. Reduction in intraocular pressure after excimer laser photorefractive keratectomy. Correlation with pretreatment myopia. Ophthalmology. 1997; 104 : 355-359.

9. Aghaian E, Choe JE, Lin S, Stamper RL. Central corneal thickness of Caucasians, Chinese, Hispanics, Filipinos, African Americans, and Japanese in glaucoma clinic. Ophthalmology. 2004;11:2211-2219.
10. Brandt JD, Beiser JA, Kass MA, Gordon MO. Central corneal thickness in the Ocular Hypertension Treatment Study (OHTS). Ophthalmology. 2001;108:1779-1788.

11. Shimmyo M, Ross AJ, Moy A, Mostafavi R. Intraocular pressure, Goldmann applanation tension, corneal thickness, and corneal curvature in Caucasians, Asians, Hispanics, and African Americans. Am J Ophthalmol. 2003;136:603-613.

12. Detry-Morel M. Utilité de la pachymétrie cornéenne dans l'hypertension oculaire et le glaucome chronique. Bull Soc Belge Ophtalmol. 2004; 293:1-9.

13. Iliev ME, Meyenberg A, Buerki E, Shafranov G, Shields MB. Novel pressure-to-cornea index in glaucoma. Br J Ophthalmol. 2007;9: 1364-1368.

14. Damji KF, Muni RH, Munger RM. Influence of corneal variables on accuracy of intraocular pressure measurement. J Glaucoma. 2003;12: 69-80.

15. Doughty MJ, Zaman ML. Human corneal thickness and its impact on intraocular pressure measures: A review of meta-analysis approach. Surv Ophthalmol. 2000;44:367-408.

16. La Rosa F, Gross RL, Orengo-Nania S. Central corneal thickness of Caucasians and African Americans in glaucomatous and non glaucomatous populations. Arch Ophthalmol. 2001;119:23-27.

17. Nemesure B, Wu SY, Hennis A, Leske C. Corneal thickness and intraocular pressure in the Barbados Eye Studies. Arch Ophtalmol. 2003;121:240-244.

18. Wolfs RCW, Klaver CCW, Vingerling JR, Grobbee DE, Hofman A, De Jong PTVM. Distribution of central corneal thickness and its association with intraocular pressure: The Rotterdam Study. Am J Ophthalmol. 1997; 123:767-772.

19. Foster Paul J, Baasanhu J, Alsbirk PH, Munkhbayar D, Uranchimeg D, Johnson GJ. Central corneal thickness and intraocular pressure in Mongolian population. Ophthalmology. 1998;105:969-973.

20. Cho P, Lam C. Factors affecting the central corneal thickness of Hong Kong-Chinese. Curr Eye Res. 1999;18:368-374.

21. Suzuki S, Suzuki Y, Iwase A, Araie M. Corneal thickness in an ophthalmologically normal Japanese population. Ophthalmology. 2005;112: 1327-1336.

22. Casson RJ, Abraham LM, Newland HS, et al. Corneal thickness and intraocular pressure in a nonglaucomatous Burmese Population. The Meiktila Eye Study. Arch Ophthalmol. 2008;126:981-985.

23. Hansen FK. A clinical study of the normal human central corneal thickness. Acta Ophthalmol (Copenh). 1971;49:82-89.

24. Korey M, Gieser D, Kass MA, Waltman SR, Gordon M, Becker B. Central corneal endothelial cell density and central corneal thickness in ocular hypertension and primary open angle glaucoma. Am J Ophthalmol. 1982;94:610-616.

25. Alsbirk PH. Corneal thickness. 2. Environmental and genetic factors. Acta Ophthalmol. 1978;56:105-113.

26. Shepens G, Urier N, Bechetoille A, De Potter P. Correlation entre tonométrie de Goldmann et tonométrie non-contact en fonction de l'épaisseur cornéenne. Bull Soc Belge Ophthalmol. 2001;279:15-19. French. 
27. Johnson M, Kass MA, Moses RA, Grodzki WJ. Increased corneal thickness simulating elevated intraocular pressure. Arch Ophthalmol. 1978;96:664-665.

28. Eysteinsson T, Jonasson F, Sasaki H, et al. Reykjavik Eye Study Group. Central corneal thickness, radius of the corneal curvature and intraocular pressure in normal subjets using non contact techniques: Reykjavick Eye Study. Acta Ophthalmol Scand. 2002;80:11-15.

29. Hahn S, Azen S, Ying-Lai M, Varma R. Central corneal thickness in Latinos. Invest Ophthalmol Vis Sci. 2003;44:1508-1512.
30. Shah S, ChatterjeeA, Mathai M, et al. Relationship between corneal thickness and measured intraocular pressure in a general ophthalmology clinic. Ophthalmology. 1999;106:2154-2160.

31. Bron AM, Creuzot-Garchet C, Goudeau-Boutillon S, d'Athis P. Falsely elevated intraocular pressure due to increased central corneal thickness. Graefes Arch Clin Exp Ophthalmol. 1999;237:220-224.

32. Foster Paul J, Wong JS, Wong E, Chen FG, Machin D, Chew PT. Accuracy of clinical estimates of intraocular pressure in Chinese eyes. Ophthalmology. 2000;107:1816-1821.
Clinical Ophthalmology

\section{Publish your work in this journal}

Clinical Ophthalmology is an international, peer-reviewed journal covering all subspecialties within ophthalmology. Key topics include: Optometry; Visual science; Pharmacology and drug therapy in eye diseases; Basic Sciences; Primary and Secondary eye care; Patient Safety and Quality of Care Improvements. This journal is indexed on

\section{Dovepress}

PubMed Central and CAS, and is the official journal of The Society of Clinical Ophthalmology (SCO). The manuscript management system is completely online and includes a very quick and fair peer-review system, which is all easy to use. Visit http://www.dovepress.com/ testimonials.php to read real quotes from published authors. 